\title{
Other PHAC publications
}

Researchers from the Public Health Agency of Canada also contribute to work published in other journals and made available elsewhere. Look for the following articles and tools published in 2020:

Boutin A, Cherian A, Liauw J, Dzakpasu S, [...] for the Canadian Perinatal Surveillance System (Public Health Agency of Canada). Database autopsy: an efficient and effective confidential enquiry into maternal deaths in Canada. J Obstet Gynaecol Can. 2020;S17012163(20)30584-3. https://doi.org/10.1016/j.jogc.2020.06.026

Dufner TJ, Fitzgerald JS, Lang JJ, Tomkinson GR. Temporal trends in the handgrip strength of 2,592,714 adults from 14 countries between 1960 and 2017: a systematic analysis. Sports Med. 2020;50(12):2175-91. https://doi.org/10.1007/s40279-020-01339-Z

Schroth RJ (commissioned by the Office of the Chief Dental Officer of Canada). Canadian Caries Risk Assessment Tool ( $<6$ years). Winnipeg (MB): Rady Faculty of Health Sciences, University of Manitoba; 2020. Available from: https://umanitoba.ca/CRA_Tool_ ENG_Version.pdf

Tugwell P, Welch VA, Karunananthan S, [...] Avey MT, et al. When to replicate systematic reviews of interventions: consensus checklist. BMJ. 2020;370:m2864. https://doi.org/10.1136/bmj.m2864 